\title{
XIII Krajowe Forum Informacji Naukowej i Technicznej w Zakopanem „Informacja naukowa na jednolitym rynku cyfrowym. Badania - rozwój - innowacje" (Zakopane, 23-25 września 2015 r.)
}

W ostatnim tygodniu września Polskie Towarzystwo Informacji Naukowej zorganizowało w Zakopanem kolejne już - XIII Forum Informacji Naukowej i Technicznej. Współorganizatorami konferencji były zakłady naukowe dwóch polskich wyższych uczelni: Zakład Zarządzania Informacją Instytutu Informacji Naukowej i Bibliotekoznawstwa Uniwersytetu Jagiellońskiego (IINiB UJ) oraz Zakład Zarządzania Informacją Instytutu Bibliotekoznawstwa i Informacji Naukowej Uniwersytetu Śląskiego (IBiIN UŚ). Tradycyjnie już współorganizatorem Forum była też Polska Sekcja ISKO - Międzynarodowego Towarzystwa Organizacji Wiedzy. Do Rady Programowej zaproszeni zostali profesorowie bibliologii i informatologii z różnych ośrodków akademickiego kształcenia w tej dyscyplinie: prof.dr hab. Wiesław Babik (Uniwersytet Jagielloński), dr hab. Hanna Batorowska, prof.UP (Uniwersytet Pedagogiczny w Krakowie), dr hab. Mirosław Górny, prof.UAM (Uniwersytet Adama Mickiewicza w Poznaniu), dr hab. Bożena Koredczuk, prof.UWr (Uniwersytet Wrocławski), dr hab. Katarzyna Materska, prof.UKSW (Uniwersytet Kardynała Stefana Wyszyńskiego), dr hab. Diana Pietruch-Reizes (Uniwersytet Jagielloński), dr hab. Maria Próchnicka (Uniwersytet Jagielloński), dr hab. Remigiusz Sapa (Uniwersytet Jagielloński), dr hab. Marta Skalska-Zlat, prof.UWr (Uniwersytet Wrocławski), prof.dr hab. Barbara Sosińska-Kalata (Uniwersytet Warszawski), dr hab. Anna Tokarska (Uniwersytet Śląski) oraz prof.dr hab. Jadwiga Woźniak-Kasperek (Uniwersytet Warszawski).

Atmosfera Grand Hotelu Stamary w Zakopanem sprzyjała obradom, a także dyskusjom kuluarowym, które w znacznym stopniu rozszerzyły i wzbogaciły wartość naukową tematów podejmowanych w referatach.

Obrady konferencyjne rozpoczęła sesja plenarna moderowana przez dr hab. Katarzynę Materską, prof. UKSW (Biblioteka UKSW w Warszawie), w której wygłoszono sześć referatów, w tym dwa wystąpienia gości zagranicznych. Mieczysław Muraszkiewicz (Instytut Informatyki Politechniki Warszawskiej) w pierwszym z nich (Yotta - A Journey Towards the Fifth Paradigm) zawarł tezę, że najważniejsze w nauce i technice są fundamentalne idee, powodujące zmiany w rozumieniu natury i roli nauki oraz sposobów jej uprawiania, a nie metody, rozwiązania i artefakty. W drugim ze swoich wystąpień prelegent podjął dyskusję związaną z pojęciem tzw. cyfrowego humanizmu, które miałoby być w nadchodzących latach i dekadach wzmocnionym znaczeniowo odpowiednikiem historycznego pojęcia humanizmu. Horatiu Dragomirescu, gość z Bucharest University of Economic Studies w Rumunii (Fee or Free? Arguments and Counter-Arguments in the debate on access regimes for scientific information) przeanalizował wybrane aspekty różnych modeli dostępu do informacji naukowych, od modelu wolnego dostępu do płatnych systemów. Kolejny prelegent sesji plenarnej, Tibor Koltay z Department of Information and Library Studies Szent István University na Węgrzech (Research 2.0, research data services and academic libraries) przedstawił problematykę badań 2.0, ich miejsca we współczesnej nauce, a także - nowe wyzwania stawiane bibliotekom akademickim w środowisku nauki 2.0. K. Materska (Biblioteka UKSW) podjęła tematykę nauki i jej zmian w drugiej dekadzie XXI wieku. Przedstawiła, m.in., problemy przemian w zagospodarowywaniu naukowej cyberprzestrzeni, sposobach prowadzenia badań, funkcjonowaniu zespołów naukowych, budowaniu infrastruktury badawczej, pozyskiwaniu wiedzy, czy też dystrybucji naukowych treści. W. Babik z IINiB UJ w referacie Rola i znaczenie ekologii informacji w społeczeństwie informacji $i$ wiedzy kontynuował wcześniej już podejmowany przez siebie temat ekologii informacji. 
W drugim dniu Forum zaprezentowano dwadzieścia referatów w ramach czterech sesji tematycznych: „Systemy informacyjne”, „Informacja naukowa - problemy badawcze”, „Informacja naukowa aspekty etyczne i prawne”, „Usługi informacyjne, biblioteki, digitalizacja”.

W czasie pierwszej sesji „Systemy informacyjne”, moderowanej przez dr hab. Hannę Batorowską, prof.UP (UP w Krakowie) wygłoszono cztery referaty. Adam Pawłowski (IINiB UWr) omówił problematykę związaną z analizowaniem dużych zestawów tekstów za pomocą dostępnych narzędzi umożliwiających automatyczne ustalanie autorstwa tekstów anonimowych, tworzenie indeksów, analizowanie relacji między dokumentami oraz zaawansowane przeszukiwanie (Korpus tekstów jako źródto informacji. Przykład narzędzi i zasobów wytwarzanych w ramach konsorcjum CLARIN-PL). Stanisław Skórka (Biblioteka Główna UP w Krakowie) przedstawił i porównał wybrane przykłady narzędzi ułatwiających tzw. odkrywanie drogi prowadzącej do poszukiwanych informacji w systemach informacyjno-wyszukiwawczych, takich jak: OPAC, biblioteki cyfrowe, bazy danych (Wayfinding - czyli o architekturze w systemach informacji). Prelegent podjął próbę odpowiedzi na pytanie, czy narzędzia mające ułatwić ludziom odkrywanie dróg w systemach informacyjnych rzeczywiście spełniają swoją funkcję? Z kolei Anna Seweryn (IBiIN UŚ) zaprezentowała stosunkowo nowe jeszcze i słabo zbadane zagadnienia infografiki (Infografika jako metoda prezentacji informacji), natomiast Jolanta Szulc (również IBiIN UŚ) $\mathrm{w}$ referacie Zarzadzanie informacja w systemach sztucznej inteligencji na podstawie literatury przedmiotu przedstawiła analizę różnych ujęć informacji w systemach z elementami sztucznej inteligencji (SI).

W ramach drugiej sesji, moderowanej przez prof. W. Babika (IINiB UJ) i poświęconej problemom badawczym informacji naukowej, przedstawiono siedem referatów. Agnieszka Korycińska-Huras z IINiB UJ w powiazaniu z pojęciem homeostazy naświetliła pojęcie naturalnego środowiska człowieka, sformułowane przez prof. Wiesława Babika, z perspektywy informatologii, neuronauk i zdrowia publicznego (Pojęcie naturalnego środowiska informacyjnego człowieka). Arkadiusz Pulikowski z IBiIN UŚ zaproponował własny model zbierania informacji, który łączy cechy kilku modeli znanych z literatury (Modele zbierania informacji wśród modeli zachowań informacyjnych). Kacper Trzaska (Biblioteka Narodowa - BN) w wystąpieniu Kategoryzowanie społecznościowe - dobry pomyst na trudne czasy? (przeglad badań) zaprezentował wyniki przeglądu literatury na temat kategoryzowania społecznościowego. Materiał badawczy stanowiły publikacje naukowe udostępnione w trzech pełnotekstowych bazach danych - ProQuest, Taylor \& Francis, JSTORE. Jarosław Pacek (również BN) omówił wynik analizy definicji terminu „książka” oraz określeń jej typów, w różnych źródłach, m.in. encyklopedycznych, słownikowych, podręcznikowych, a także w kontekście wypowiedzi potocznych (Pole semantyczne książki w tekstach normalizacyjnych i prawnych). Referat S. Cisek (IINiB UJ), poświęcony był metodzie zdarzeń krytycznych (ang. Critical Incident Technique, CIT) w badaniach Information Literacy w latach 2001-2015, w oparciu o literaturę anglojęzyczną. Ostatnie wystąpienie w tej sesji, H. Batorowskiej (UP w Krakowie), zostało poświęcone kulturze informacyjnej społeczeństwa, określonej jako podstawowy komponent kultury bezpieczeństwa (Kultura informacyjna w naukach o bezpieczeństwie).

$\mathrm{Na}$ trzecią sesję tematyczną pierwszego dnia konferencji, moderowaną przez prezes PTIN, dr hab. Dianę Pietruch-Reizes (IINiB UJ) i poświęconą aspektom prawnym i etycznym informacji naukowej, składały się dwa referaty. D. Pietruch-Reizes (IINiB UJ) w prezentacji Jednolity rynek cyfrowy omówiła ustalenia Unii Europejskiej, odnoszące się do kształtowania jednolitego rynku cyfrowego. Tematem referatu Ewy Dobrogowskiej-Schlebusch i Barbary Niedźwiedzkiej z Collegium Medicum UJ, zatytułowanego Problemy etyczne zwiazane z wykorzystaniem treści publikowanych w serwisach społecznościowych jako źródła badań jakościowych w naukach medycznych i naukach o zdrowiu był etyczny wymiar wykorzystywania w badaniach jakościowych treści z zakresu medycyny i ochrony zdrowia, publikowanych w społecznym Internecie. Wygłaszająca referat E. Dobrogowska-Schlebusch przedstawiła wytyczne postępowania dotyczące posługiwania się w badaniach tego typu wrażliwymi danymi.

Ostatnia sesja pierwszego dnia konferencji poświęcona została tematowi „Usługi informacyjne, biblioteki, digitalizacja", w jej ramach wygłoszono sześć referatów, a prowadzenie sesji powierzono dr hab. Bożenie Koredczuk, prof.UWr (IINiB UWr). W pierwszym z referatów Małgorzata Janiak (IINiB 
UJ) zaprezentowała różne aspekty funkcjonowania bibliotek cyfrowych, a także przedstawiła wnioski z analiz scenariuszy rozwoju bibliotek cyfrowych oraz tezy odnoszące się do ich przyszłości (Przyszłość bibliotek cyfrowych). Agnieszka Łakomy (IBiIN UŚ) w wystąpieniu Zarządzanie dokumentami elektronicznymi $w$ bibliotekach przedstawiła przykłady inicjatyw polegających na gromadzeniu dokumentów elektronicznych o dostępie zdalnym w wybranych bibliotekach narodowych w Europie i na świecie. Kolejna prelegentka z IBiIN UŚ, Izabela Swoboda, w referacie Serwisy DiscoveryEDelivery w bibliotekach akademickich szkót publicznych w Polsce zaprezentowała wyniki badań nad efektywnością tego typu serwisów coraz częściej spotykanych w polskich bibliotekach akademickich. Tematem wystąpienia Anny Myśliwskiej z BN były problemy (korzyści i niedogodności) cyfrowego systemu wypożyczeń międzybibliotecznych (Chronić czy udostępniać? Cyfrowy system wypożyczeń międzybibliotecznych remedium na ograniczenia w dostępie do publikacji naukowych). Podjęta została również próba odpowiedzi na pytania: Czy Academica udostępniając publikacje naukowe, rzeczywiści chroni zbiory Biblioteki Narodowej? Oraz jakie są konsekwencje wprowadzenia elektronicznego systemu wypożyczeń dla bibliotek i użytkownika?

Drugi dzień obrad zakończony został kolacją regionalną, w czasie której kontynuowano dyskusję nad tezami przedstawionymi w trakcie obrad.

Trzeci dzień konferencji rozpoczął się panelem tematycznym „Informacja naukowa w instytutach badawczych", prowadzonym przez dr Renatę Frączek (IBiIN UŚ). Najpierw zaprezentowano raport z działalności PTIN - Polskiego Towarzystwa Informacji Naukowej. Omówiono dane nt. uczestnictwa na wszystkich Forach INT, jak i publikowania tekstów przez przedstawicieli instytutów badawczych w Polsce w materiałach i monografiach pokonferencyjnych Forum. Następnie Joanna Szewczykiewicz z Instytutu Badawczego Leśnictwa (Otwarty dostęp do publikacji i danych naukowych pracowników Instytutu Badawczego Leśnictwa) omówiła znaczenie dostępu do wyników badań i opracowań naukowych instytutu dla efektów badań naukowych oraz działania mające na celu integrację wielu danych związanych z leśnictwem polskim i utworzeniem multiwyszukiwarki. Kolejne cztery referaty zostały zaprezentowane przez przedstawicieli Centralnego Instytutu Ochrony Pracy - Państwowego Instytutu Badawczego (CIOP-PIB). Witold Sygocki (Źródta informacji o publikacjach w zakresie bezpieczeństwa pracy udostępnianych w bazach Web of Science CC i Scopus oraz innych zasobach) sprawdził występowanie i dostępność pełnych tekstów materiałów w zakresie tematyki bezpieczeństwa w pracy w bazach Web of Science, Scopus oraz w przestrzeni internetowej. Marek Poźniak (Publikacje cyfrowe Europejskiej Agencji Bezpieczeństwa $i$ Zdrowia $w$ Pracy w katalogu elektronicznym Biblioteki CIOP-PIB) zaprezentował prace digitalizacyjne prowadzone w CIOP, omówił ich cele oraz plany związane z włączeniem cyfrowych kopii publikacji Europejskiej Agencji Bezpieczeństwa i Zdrowia w Pracy, mającej siedzibę w Bilbao. Barbara Szczepanowska przedstawiła bazy danych z zakresu problematyki pracy jako ważne wsparcie w procesach edukacyjnych, naukowych i praktycznych (Wykorzystanie technologii cyfrowych do upowszechniania informacji w ramach wspótpracy międzynarodowej na przykładzie wybranych baz danych). Z kolei Agnieszka Młodzka-Stybel (Zastosowanie multiwyszukiwarki PRIMO w bibliotekach krajowych - przykłady) omówiła przykłady zastosowań multiwyszukiwarki PRIMO oraz konieczność doskonalenia funkcjonalności wyszukiwania.

Kolejną częścią konferencji był odbywający się po raz pierwszy w historii Forum „Panel studentów i doktorantów informatologii”. Moderował go dr Stanisław Skórka (Biblioteka UP w Krakowie). Pierwsza prelegentka, Dorota Rak (IINiB UJ) nie dotarła na Forum, jednak uczestnicy konferencji obejrzeli przekazany organizatorom film zawierający prezentację, opatrzoną komentarzami głosowymi referentki (Polskie biblioteki uczelniane w procesie komunikacji naukowej). Rozważała ona rolę biblioteki w działalności i komunikacji naukowej, analizując działania w tym zakresie (udział i organizacja konferencji, działalność wydawnicza oraz wykorzystanie nowych mediów) bibliotek ze 129 polskich uczelni publicznych w latach 2010-2014. Następnie uczestnicy wysłuchali prezentacji Joanny Płaszewskiej (IINiB UJ), która na podstawie studium przypadku tagu konferencji DiGRA 2015 omówiła live-tweeting jako coraz popularniejszą formę komunikacji na międzynarodowych konferencjach (Live-tweeting jako narzędzie komunikacji naukowej. Case study tagu \#digra2015"). Monika Halasz-Cysarz (IINiSB UW) zaprezentowała referat Etyka informacyjna a e-government. Prelegentka najpierw omówiła interdyscyplinarność 
etyki informacyjnej, rozwijającej się na świecie od ok. 30 lat, a potem możliwości, które niesie ona dla działań związanych z wdrażaniem wysokich etycznie standardów funkcjonowania e-administracji w Polsce. Elżbieta Sroka oraz Katarzyna Trojańczyk (IBiIN UŚ) w referacie E-learning a otwartość zasobów. Rozważania teoretyczne zaprezentowały analizę zakresu pojęciowego oraz zastosowań w piśmiennictwie terminów: e-learning, otwarta nauka, otwarty zasób edukacyjny. Ostatnią prezentacją w sesji był referat Magdaleny Zych (IINiB UJ) Mechanika kwantowa jako metafora utrudnień metodologicznych w User Experience i informatologii. Autorka omówiła ryzyko tendencyjności wyników, zasadę nieoznaczoności Heisenberga oraz paradoks "dylematu hedonistycznego" w kontekście projektowania i prowadzenia badań User Experience.

Ostatnia sesja konferencji, moderowana przez dr. S. Skórkę (BG UP w Krakowie), poświęcona była informacji specjalistycznej. Maria Fuzowska-Wójcik oraz Danuta Rytel z Urzędu Patentowego RP omówiły korzyści płynące z procesu digitalizacji prowadzonej w ich macierzystej instytucji (Digitalizacja dokumentacji patentowej w Urzędzie Patentowym RP). Lidia Derfert-Wolf (Uniwersytet Technologiczno-Przyrodniczy w Bydgoszczy) i Dorota Buzdygan (Biblioteka Politechniki Krakowskiej) zaprezentowały film promujący BazTech oraz omówiły sposoby i skuteczność promocji zasobów otwartej nauki na podstawie tej bazy bibliograficznej. Kolejny prelegent, Mariusz Luterek (IINiSB UW), omówił wyniki badania ankietowego dotyczącego opinii bibliotekarzy na temat możliwości pełnienia przez biblioteki funkcji pośrednika w dostępie do informacji i usług publicznych, przeprowadzonego wśród bibliotekarzy trzech województw: mazowieckiego, małopolskiego oraz świętokrzyskiego (Biblioteki jako pośrednicy $w$ dostępie do elektronicznych informacji i ustug publicznych. Opinie bibliotekarzy). Ostatni referat Forum pt. Adaptacja meta danych AGRO do Polskiej Bibliografii Naukowej i POL-indeksu - intensyfikacja walorów informacyjnych i użytkowych bazy AGRO, autorstwa Krzysztofa Gmerka (Biblioteka Główna, Centrum Informacji Naukowej Uniwersytetu Przyrodniczego w Poznaniu) wywołał szeroką dyskusję na gorący wówczas temat wprowadzania danych do bazy POL-index.

Konferencję zamknęli prof. W. Babik oraz dr hab. D. Pietruch-Reizes podsumowując obrady XIII Forum PTIN i zapraszając wszystkich na kolejne Forum w 2017 r., którego tematem przewodnim mają być kierunki badań podejmowane i omawiane przez zmarłą kilka miesięcy przed Forum w Zakopanem prof. Wandę Pindlową, jedną z pionierek polskiej informatologii (nauki o informacji), wieloletniego pracownika Uniwersytetu Jagiellońskiego. W kuluarach nadal toczyły się ożywione dyskusje, uczestnicy mieli okazję zapoznania się z dwoma posterami, które w tym roku zostały zaprezentowane na Forum: Działania Biblioteki Uniwersyteckiej w Poznaniu na rzecz społeczności UAM w zakresie komunikacji naukowej (Aldona Chachlikowska, Biblioteka Uniwersytecka w Poznaniu) oraz Czytniki e-książek w praktyce biblioteki uczelnianej (przykład Wyższych Szkót Bankowych w Toruniu $i$ Bydgoszczy) autorstwa Julity Niedźwieckiej-Ambroziak z WSB w Toruniu.

W Forum wzięło udział ponad 50 osób, przedstawicieli większości polskich ośrodków akademickiego kształcenia pracowników informacji i bibliotekarzy. Wśród uczestników znaleźli się przede wszystkim członkowie i działacze PTIN, członkowie ISKO, twórcy i użytkownicy informacji naukowej, bibliotekarze oraz osoby z obszarów pokrewnych. W 8 sesjach (sesja plenarna +5 sesji tematycznych + 1 panel tematyczny + 1 panel studentów i doktorantów) wygłoszono łącznie 37 referatów i komunikatów naukowych. Można mieć nadzieję, że XIII Forum INT w Zakopanem stanie się źródłem intelektualnych aspiracji i dalszej naukowej refleksji.

Renata Frączek Instytut Bibliotekoznawstwa i Informacji Naukowej, Uniwersytet Śląski w Katowicach

Monika Halasz-Cysarz Instytut Informacji Naukowej i Studiów Bibliologicznych, Uniwersytet Warszawski

Nadestano: 23 stycznia 2016. 